\title{
Regeneration in the central nervous system
}

\author{
Christine E. Bandtlow* \\ Division of Neurobiochemistry, Institute of Medical Chemistry and Biochemistry, Leopold-Franzens-University of Innsbruck, Fritz-Pregl-Str. 3, \\ A-6020 Innsbruck, Austria
}

Received 25 June 2002; accepted 3 July 2002

\begin{abstract}
Unlike neonatal axons, mammalian adult axons of the CNS do not regenerate after injury. This developmental loss of regenerative capacity, is correlated with the onset of myelination. Likewise, myelin, or myelin-associated components such as Nogo-A and myelinassociated glycoprotein (MAG) inhibit regeneration from older but not younger neurons. Identification of the molecular events responsible for this developmental loss of regenerative capacity is central to devise strategies to encourage regeneration in adults after injury. Endogenous levels of the cyclic nucleotides cAMP and cGMP have been suggested to determine the neuronal responsiveness to various axonal guidance factors. Elevating cAMP concentrations block Nogo-A or MAG induced inhibition of neurite outgrowth in older neurons, whereas suppressing cAMP levels in young neurons renders them susceptible to Nogo-A and MAG. Interestingly, elevated cAMP levels abrogated the Nogo-A and MAG mediated activation of RhoA and down regulation of Rac1 in adult neurons. In contrast, elevation of cAMP leads to the inactivation of RhoA and prevents activation of downstream effector proteins, while Rac is activated. We therefore conclude that the endogenous neuronal cAMP levels determine the neuronal responsiveness to myelin-associated neurite growth inhibitors by regulating rho GTPase activities.
\end{abstract}

(C) 2002 Published by Elsevier Science Inc.

Keywords: Regeneration; Development; Neurite growth inhibitors; CNS myelin; Nogo-A; Myelin-associated glycoprotein; Small GTPases; Signal transduction

\section{Introduction}

Traumatic injuries to the adult mammalian central nervous system (CNS) cause severe and irreparable disabilities. Even limited local insults to the brain or the spinal cord have devastating consequences due to the inability of the CNS to regenerate injured nerve fibers or to react with structural plasticity. Successful regeneration depends upon the ability of injured axons to survive, re-grow, and reconnect with their original targets, processes integral to normal development. Interestingly, successful regeneration giving rise to functional recovery is seen in the CNS of young mammals (Bates and Stelzner, 1993; Hasan et al., 1993). Defined spinal cord lesions in chicken embryos or newborn hamsters, opossums, cats or rats lead to extensive growth of regenerating fibers into the denervated spinal cord, whereas no such growth is observed after lesions in the adult (Kalil and Reh, 1982; Tolbert and Der, 1987; Hasan et al., 1991; Treherne et al.,

\footnotetext{
* Tel.: +43-512-507-3260; fax: +43-512-507-2874.

E-mail address: christine.bandtlow@uibk.ac.at (C.E. Bandtlow).
}

1992; Bregman et al., 1993; Saunders et al., 1998). Thus, adult neurons seem to loose this ability during late postnatal development and the regenerative response becomes abortive. Changes in the cellular environment as well as in the neuronal response to that environment have been suggested to account for the absence of regeneration of mature axons (Keirstead et al., 1992; Li and Raisman, 1993; Schwab and Bartholdi, 1996). However, in general adult CNS neurons have not lost the intrinsic capacity to regrow, because, when provided with a permissive environment, they will extend long processes (Richardson et al., 1980; David and Aguayo, 1981; Crutcher, 1989; Schnell and Schwab, 1990). Thus, the expression of new factors or components at later stages of CNS development seem to contribute to a hostile environment for axonal growth after injury. One obvious candidate that appears with late development in the CNS is myelin. Indeed, the end of the regeneration-permissive period in many species correlates in time with the appearance of the first differentiated oligodendrocytes and the onset of myelination. Several in vivo studies showed that the growth-permissive period that allows regeneration and functional recovery can 
be extended either when development of oligodendrocytes was experimentally prevented by $\mathrm{X}$-irradiation, or when the start of myelination was delayed by immunocytolysis of myelin (Savio and Schwab, 1990; Keirstead et al., 1992, 1995). Another strong evidence that components of CNS myelin are key players in preventing regeneration is the extensive regeneration that occurred in mice immunized with purified CNS myelin before spinal cord transection (Huang et al., 1999). The myelin antibodies may neutralize myelinspecific inhibitors of regrowth, allowing regeneration to commence immediately after injury. Myelin-associated components, may however not only impair regenerative responses, but they may also be involved in suppressing sprouting and plastic changes of synaptic terminals (Kapfhammer and Schwab, 1994a,b).

The search for the molecular components present in CNS myelin that prevent regeneration has led to the identification of two molecules that act as potent neurite growth inhibitors in vitro: the recently cloned molecule Nogo-A (formerly called NI-220) and the myelin-associated glycoprotein (MAG) (Chen et al., 2000; GrandPré et al., 2000; Prinjha et al., 2000; Mukhopadhyay et al., 1994; McKerracher et al., 1994). Nogo-A, the largest transcript of the recently identified nogo gene, is a transmembrane protein mainly expressed by oligodendrocytes and certain subpopulations of neurons (Huber et al., 2002). Biochemical analysis revealed that the inhibitory activity of Nogo-A resides both in the N-terminal part of the molecule called $\mathrm{NiG}$ (Chen et al., 2000; Prinjha et al., 2000) and in the Nogo-66 domain, a stretch of 66-amino acids spanning the two putative transmembrane domains (GrandPré et al., 2000; Fournier et al., 2001). Moreover, NiG consists of several discrete regions that exhibit diverse inhibitory properties in vitro, the most potent being a 181 amino acid region (NiG- $\Delta 20$ ) (Oertle et al., 2001; Oertle et al., submitted). MAG, a member of the Ig-superfamily, was originally described as a neurite outgrowth promoting molecule for a number of different neurons (Johnson et al., 1989). More recent data show that MAG acts as a bifunctional protein that can either promote or inhibit neurite outgrowth depending on the neuronal age (Mukhopadhyay et al., 1994; DeBellard et al., 1996; Turnley and Bartlett, 1998). The most convincing evidence that such inhibitors indeed contribute to a hostile environment for regenerating nerve fibers in vivo comes from experiments showing that function blocking antibodies directed against Nogo-A led to robust extension of regenerating nerve fibers in the rat spinal cord, giving rise to functional recovery (Bregman et al., 1995). Subsequent studies also showed that the plasticity of axons in uninjured pathways was enhanced, allowing for growth into injured areas where they may assist in restoration of function (Zagrebelsky et al., 1998; Thallmair et al., 1998; Z'Graggen et al., 1998). Myelin or the above mentioned neurite growth inhibitors do not exert this inhibitory effect on embryonic neurons, either in culture (Shewan et al., 1995; Bandtlow and Löschinger, 1997), or when transplanted in vivo ( $\mathrm{Li}$ and
Raisman, 1993). Thus, the identification of the molecular difference between embryonic and adult neurons that is responsible for this change in neuronal responsiveness and regenerative capacity may help to design strategies to induce adult axons to regrow after injury.

\section{Materials and methods}

\subsection{Expression vectors}

Cloning and expression of recombinant rat NiG (aa 174979) and of the coding sequence for rat Nogo-66 (aa 10261091 of rat Nogo-A) into the appropriate expression vectors was described previously (Oertle et al., submitted).

\subsection{Neurite outgrowth assays}

Cerebellar granule cells from postnatal day 1 or 7 rat pups were dissociated by combined trituration and trypsinization as described (Hatten, 1985). Cells were plated on 4-well tissue culture dishes (Greiner) coated with recombinant substrate proteins and neurite outgrowth was scored as described (Niederöst et al., 1999). Addition of cyclic nucleotide analogs were performed as described (Song et al., 1998).

\subsection{DRG-oligodendrocyte encounter assay}

DRG-oligodendrocyte encounter assay was performed as described previously (Bandtlow et al., 1990). Delivery of C3-transferase-GST fusion protein was performed as described by Borasio et al. (1989).

\subsection{Racl and RhoA activity assays}

Measurement of Rac1 and RhoA activities on cerebellar granule cells of $\mathrm{P} 1$ or $\mathrm{P} 7$ rat pups was performed as described previously (Bagrodia et al., 1995; Ren et al., 1999). Further details are described in Niederöst et al. (2002).

\section{Results and discussion}

\subsection{Neuronal age influences the responsiveness to Nogo-A}

We have previously shown that the responsiveness of neurons to purified Nogo-A (formerly called NI-220) changes as development proceeds (Bandtlow and Löschinger, 1997). Embryonic rat E13 dorsal root ganglion cells (DRG) or chick E 6/7 retinal ganglion cells (RGC) are less sensitive to Nogo-A and their growth cones collapse only transiently when exposed to Nogo-A (Fig. 1). In contrast, rat P6 or adult DRG and chick E13 RGC react with an immediate and long-lasting collapse. Likewise, when rat cerebellar granule cells were grown on substrate-bound recombinant $\mathrm{NiG}$ (extracellular part of Nogo-A), less than 

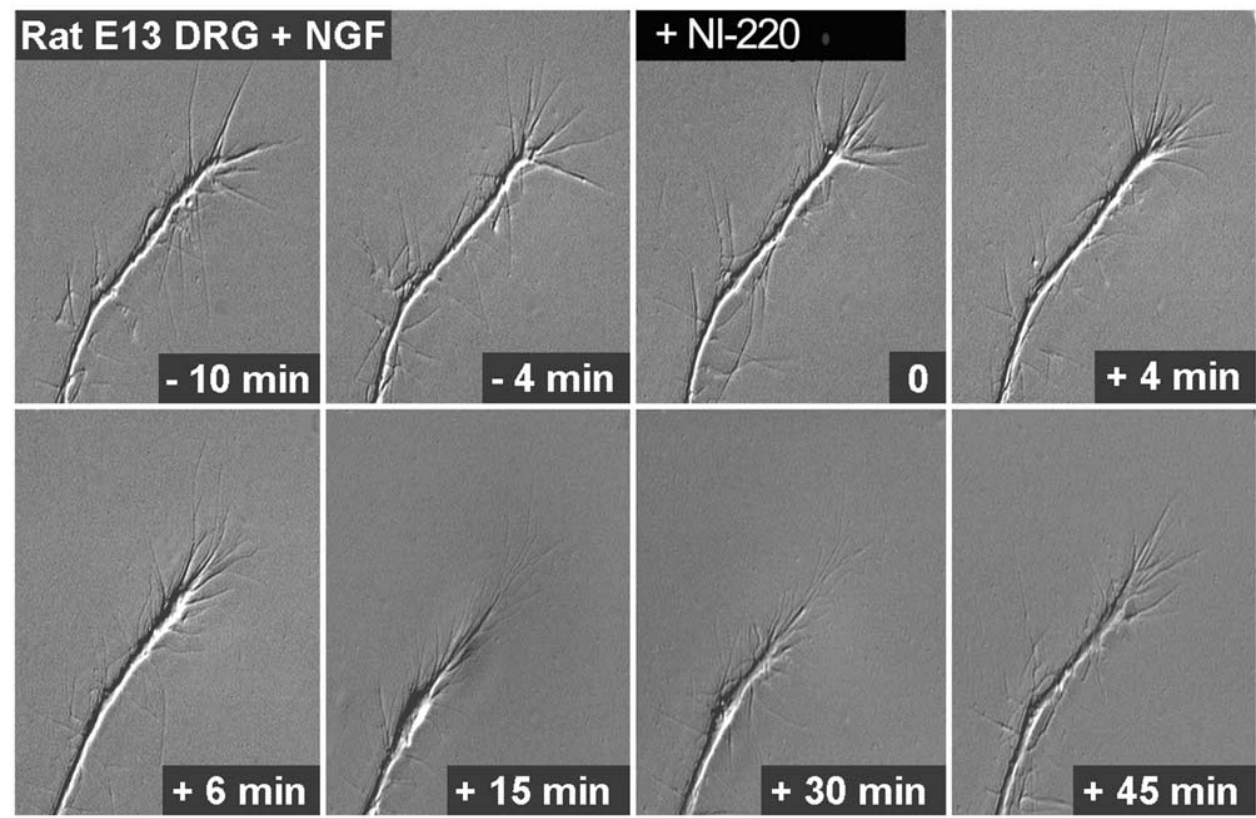

Fig. 1. Transient growth cone collapse of an E13 DRG neuron after NI-220 addition. Note that the growth cone collapses and retracts, but recovers within 30 min after NI-220 stimulation.

$25 \%$ of the mature neurons (i.e. neurons older than P5) produced neurites, while $50 \%$ of their embryonic counterparts (younger than P4) extended neurites longer than one cell body diameter (Fig. 2A-C). No age dependent difference in the response was seen between neurons when grown on the control substrates laminin or L1. Similar age-related responses were reported for neurons grown on MAG (Cai et al., 2001). Since Nogo-A and MAG are
A

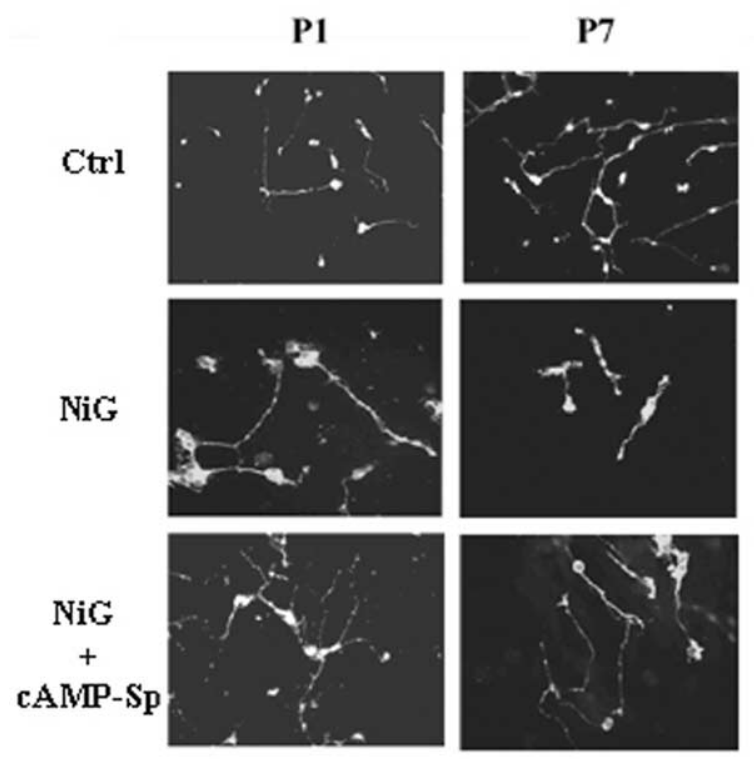

B
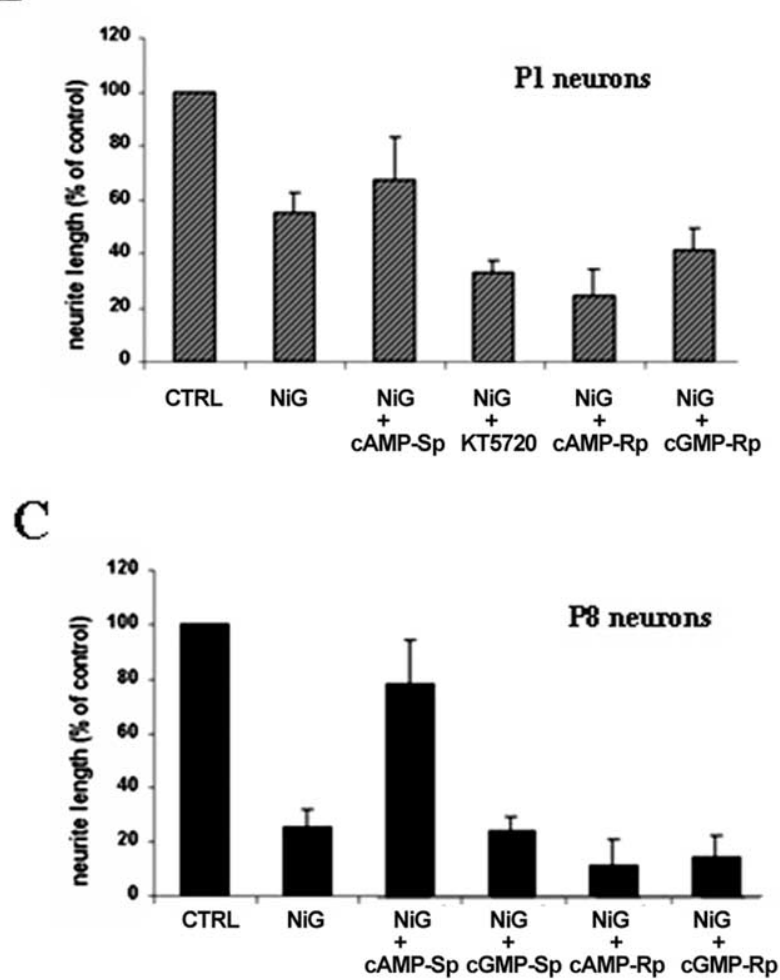

Fig. 2. Developmental age determines neurite outgrowth response of cerebellar granule cells (CGC) on NiG. (A) neurite outgrowth of CGC of P7 or P1 rat pups on NiG; note that P1 CGC are not inhibited on NiG, whereas cAMP-Sp can restore neurite outgrowth of P7 CGC on NiG. Quantification of neurite outgrowth response of P1 neurons (B) and of P7 neurons (C) in the presence or absence of cyclic-nucleotide-analogs. 
expressed on oligodendrocytes, we further addressed the age-related switch in encounter studies with fully differentiated oligodendrocytes using time lapse videomicroscopy. Filopodial contact of growth cones from mature neurons with differentiated oligodendrocytes led to growth cone collapse and retraction. In contrast, embryonic neurons could extend into and over the dense network of oligodendrocyte processes.

These data demonstrate that the ability of neurons to respond to Nogo-A changes as development proceeds. The reasons underlying this developmental change in the susceptibility to neurite outgrowth inhibition and growth cone collapse are still largely unknown. The simplest, although not exclusive explanation is that immature neurons have not yet expressed the functional receptors and/or the signal transduction mechanism(s) for Nogo-A. Support for this hypothesis was recently provided by Fournier et al. showing that transfection of embryonic RGCs with $\mathrm{NgR}$, a specific binding protein for Nogo-66, renders these neurons susceptible to Nogo-66 (Fournier et al., 2001). On the other hand it was suggested that the better growth of young neurons on CNS myelin or MAG substrate is a consequence of higher endogenous levels of cAMP relative to older neurons (Cai et al., 1999, 2001). Consistent with this observation, elevating endogenous levels of cAMP by the cAMP agonist cAMP-Sp $(500 \mu \mathrm{M})$

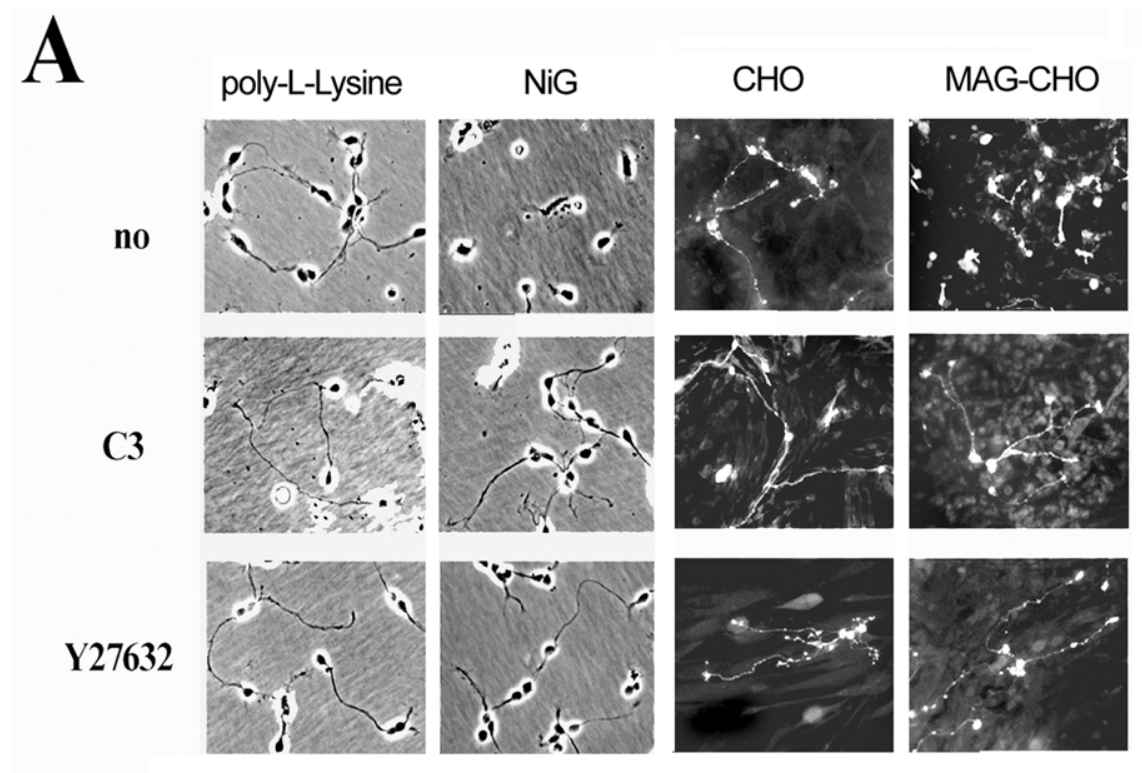

B

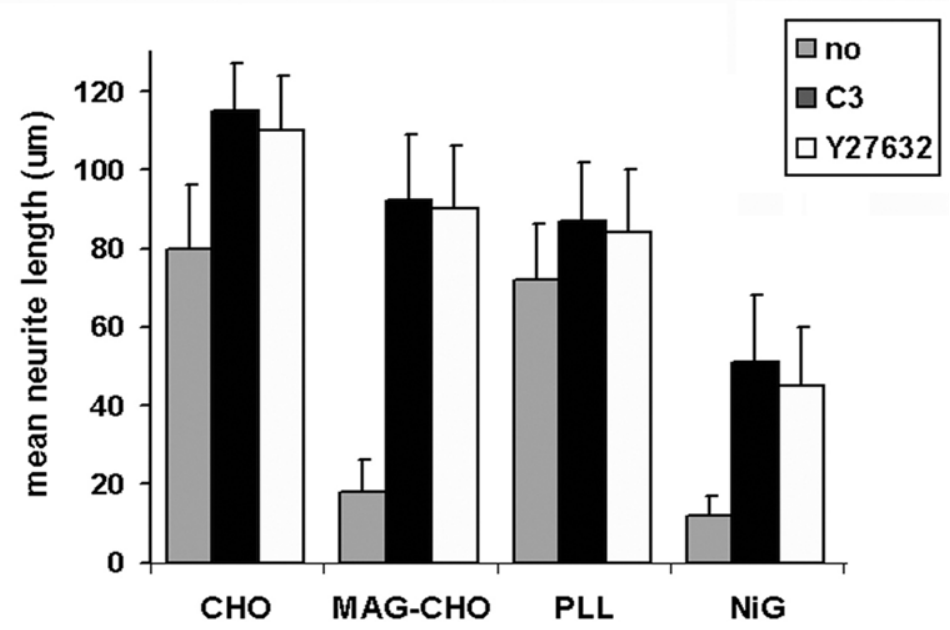

Fig. 3. RhoA dependent inhibition of neurite outgrowth of cerebellar granule cells on Nogo and MAG substrates. Analysis of the inhibitory properites of NiG and MAG-CHO. (A) Purified cerebellar granule cells of P7 rat pups were plated on control substrates poly-L-lysine (10 $\mu \mathrm{g} / \mathrm{ml})$ or CHO control cells and on the inhibitory substrates NiG $(10 \mu \mathrm{g} / \mathrm{ml})$ and on MAG-CHO cells in the absence or presence of transferase C3 or Y-27632, respectively. (B) Neurite length of at least 120 neurons per substrate was measured and presented as the mean neurite length. Note that inhibition of RhoA by C3 transferase or of Rho-kinase by Y27632 restores neurite length on all inhibitory substrates tested. 
or Forskolin $(10 \mu \mathrm{M})$ greatly facilitated neurite outgrowth of P7 cerebellar granule cells on substrate-bound $\mathrm{NiG}$, while cGMP analogs had no effect (Fig. 2A-C). To determine whether elevated levels of cAMP in newborn neurons are indeed necessary for neurite growth on $\mathrm{NiG}$, the downstream effector of cAMP, PKA, was inhibited. Both the PKA inhibitor, KT5720 (200 nM), and the cAMP antagonist, cAMP-Rp $(500 \mu \mathrm{M})$, blocked neurite outgrowth on myelin by $50 \%$; the cGMP antagonist cGMP$\mathrm{Rp}$ had no effect (Fig. 2A-C). None of these compounds had an effect on neurite outgrowth on control substrates. Taken together, these results not only suggest, that inhibition of axonal growth by NiG is cAMP-dependent, but that the endogenous levels of cAMP in cerebellar granule cells dictate the developmental switch of these neurons to inhibition.

\subsection{RhoA and ROCK mediate Nogo-A and MAG-induced neurite inhibition}

Our previous studies showed that neurite outgrowth inhibition of P7 cerebellar granule cells is mediated by small GTPases of the RhoA family (Niederöst et al., 2002). Purified P7 cerebellar granule cells are not only strongly inhibited on substrate-bound recombinant $\mathrm{NiG}$ (Nogo-A specific domain aa 174-979), but also on MAG-CHO cells. About $80 \%$ of the cells had neurites longer than $70 \mu \mathrm{m}$ on control substrates, but only $10-18 \%$ of the cells put out

\section{A}

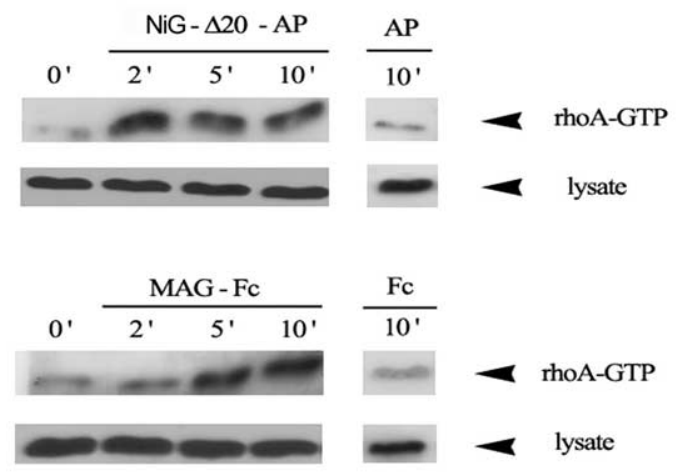

B
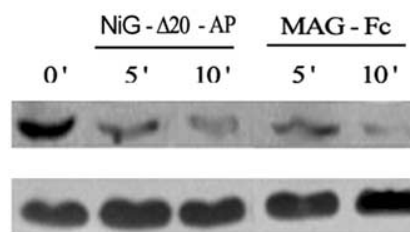

Rac1-GTP

lysate
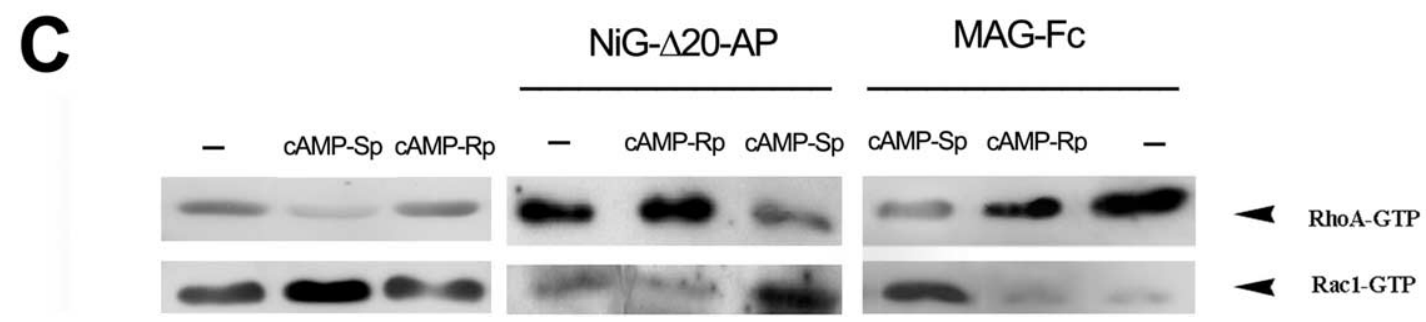

Fig. 4. Effects of NiG- $\Delta 20$ and MAG fusion proteins on RhoA and Rac1 activities in postnatal cerebellar granule cells. Dissociated cerebellar granule cells of P7 rats were grown overnight in chemically defined medium on a poly-lysine substrate before stimulation with the growth inhibitory fusion proteins of Nogo-A and MAG. Time course of RhoA (A) and Rac1 activities (B) after the addition of equal molar concentrations (120 NM) of dimeric NiG- $\Delta 20-\mathrm{AP}$ or MAG-Fc. RhoA and Rac1 activities are indicated by the amount of GST-RBD-bound RhoA or GST-CRIB-bound Rac1 normalized to the amount of total RhoA or Rac1 content in the lysates, respectively. (C) Changes of RhoA and Rac1 activities after stimulation with fusion proteins in the presence of cAMP-analogs. Note that cAMP-Sp prevents RhoA activation. 
neurites on NiG or MAG-CHO. Trituration of granule cells with $20 \mu \mathrm{g} / \mathrm{ml} \mathrm{C} 3$ transferase to inactivate endogenous RhoA activity, markedly improved the outgrowth response. Not only significantly more cells extended neurites on the inhibitory test substrates, but their neurite length was restored to untreated control levels by C3 transferase (Fig. 3A and B). Previous studies have shown that cell rounding and neurite retraction require the involvement of the RhoA-associated kinase ROCK (Hirose et al., 1998). To determine whether ROCK was involved in the MAG or Nogo-A-induced neurite growth inhibition, cerebellar granule cells were treated with various concentrations of a ROCK-selective inhibitor, Y-27632 (Ishizaki et al., 2002). While lower concentrations gave variable results, application of Y-27632 $(15 \mu \mathrm{M})$ throughout the culture period completely abolished the inhibitory effect of MAG and NiG substrates (Fig. 3A and B) and restored the length of neurites to control levels. These data suggest that RhoA and its downstream effector protein ROCK are key regulators mediating Nogo-A and MAG induced neurite outgrowth inhibition.

\subsection{Opposing regulation of RhoA and Racl by Nogo-A and $M A G$}

To directly assess the modulation of the activity of RhoGTPases by inhibitory cues, soluble, dimeric fusion proteins of the Nogo inhibitory domains and of the extracellular domain of the MAG molecule were added to cultured cerebellar granule cells and the amounts of cellular active GTP-bound RhoA and Rac1 were measured. Addition of preclustered MAG-Fc and NiG- $\Delta 20-\mathrm{AP}$, respectively, induced a rapid increase in the amount of cellular GTPbound RhoA of cerebellar granule cells. Maximal elevation was reached for NiG- $\Delta 20-\mathrm{AP}$ at $2-5 \mathrm{~min}$, and for MAG-Fc at 5-10 min (Fig. 4A). Slower activation responses were seen with unclustered fusion proteins (data not shown), but no changes were observed using preclustered AP- or Fcprotein (Fig. 4A). In contrast, the same concentrations of fusion proteins induced a small, but significant decrease in the amount of cellular GTP-bound Rac1, reaching a minimal level at 2-5 min (Fig. 4B), with no apparent recovery to basal levels over a period of $60 \mathrm{~min}$ (data not shown). The total amount of RhoA and Rac1 in each lysate (active and inactive) was almost constant. This indicates that MAG as well as the Nogo domains are oppositely regulating the activities of RhoA and Rac1, i.e. activating RhoA and suppressing Rac1.

\subsection{Elevated cAMP levels prevent Nogo-A and MAG- induced rhoA activation}

Since artificially elevating the cAMP levels in P7 neurons can block the inhibitory activity of NiG and MAG, we asked whether cAMP analogs can regulate endogenous Rho GTPase activities. cAMP-Sp and Forskolin, but not
cAMP-Rp, effectively suppressed endogenous RhoA activity and specifically abrogated MAG and Nogo-induced RhoA activation (Fig. 4C). Interestingly, cAMP not only inactivates rhoA, but activates Rac1 (Fig. 4C), which is blocked by pharmacological inhibitors of PKA (not shown). Our data suggest that increased PKA activity would facilitate Rac activation and impede Rho activation and vice versa, thus facilitating their reciprocal relationship. In non-neuronal cells cAMP/PKA metabolism was shown to negatively regulate RhoA function (Dong et al., 1998; Laudanna et al., 1997; Lang et al., 1996) by a direct phosphorylation of RhoA by PKA (Dong et al., 1998). The mechanism by which PKA stimulates Rac activation, however, is unlikely to involve its direct phosphorylation because Rac does not contain a consensus PKA phosphorylation site. PKA may regulate Rac indirectly by modifying the function of molecules that control Rac activation. For example, both Tiam-1 and Trio, which are guanine nucleotide exchange factors involved in Rac activation, have consensus PKA phosphorylation sites, and may thus provide possible links between PKA and Rac activation.

Based on these observations, we propose that the cAMP/PKA dependent signals differentially influence Rac and Rho, resulting in spatial and temporal differences in the activation of Rac and Rho. Such differences could be manifested, for example, in the Rac mediated lamellipodial protrusion necessary for axonal extension and Rhomediated contractility involved in neurite inhibition. Moreover, the counter-opposing regulation of RhoA and Rac activities could explain the developmental switch in the responsiveness of neurons to neurite growth inhibitors, such as Nogo-A and MAG.

\section{Acknowledgements}

This work was supported by the Swiss National Science Foundation (grant number 31-58398) and the Austrian National Bank (project number 9041).

\section{References}

Bagrodia, S., Derijard, Davis, R.J., Cerione, R.A., 1995. Cdc42 and PAK mediated signalling leads to Jun kinase and p38 mitogen-activated protein kinase activation. J. Biol. Chem. 270, 27995-27998.

Bandtlow, C.E., Löschinger, J., 1997. Developmental changes in neuronal responsiveness to the CNS myelin-associated neurite growth inhibitor Ni-35/250. Eur. J. Neurosci. 9, 2743-2752.

Bandtlow, C.E., Zachleder, T., Schwab, M.E., 1990. Oligodendrocytes arrest neurite growth by contact inhibition. J. Neurosci. 12, 3837-3848.

Bates, C.A., Stelzner, D.J., 1993. Extension and regeneration of corticospinal axons after early spinal injury and the maintenance of corticospinal topography. Exp. Neurol. 123, 106-117.

Borasio, G.D., John, J., Wittinghofer, A., Barde, Y.A., Sendtner, M., Heumann, R., 1989. Ras p21 protein promotes survival and 
fiber outgrowth of cultured embryonic neurons. Neuron 2, 1087-1096.

Bregman, B.S., Kunkel-Bagden, E., Reier, P.J., Dai, H.N., McAtee, M., Gao, D., 1993. Recovery of function after spinal cord injury: mechanisms underlying transplant-mediated recovery of function differ after spinal cord injury in newborn and adult rats. Exp. Neurol. 123, 3-16.

Bregman, B.S., Kunkel-Bagden, E., Schnell, L., Dai, H.N., Gao, D., Schwab, M.E., 1995. Recovery from spinal cord injury mediated by antibodies to neurite growth inhibitors. Nature 378, 498-501.

Cai, D., Shen, Y., De Bellard, M., Tang, S., Filbin, M.T., 1999. Prior exposure to neurotrophins blocks inhibition of axonal regeneration by MAG and myelin via a cAMP-dependent mechanism. Neuron 22, 89-101.

Cai, D., Qiu, J., Cao, Z., McAtee, M., Bregman, B.S., Filbin, M.T., 2001. Neuronal cyclic AMP controls the developmental loss in ability of axons to regenerate. J. Neurosci. 21, 4731-4779.

Chen, M.S., Huber, A.B., van der Haar, M.E., Frank, M., Schnell, L., Spillmann, A.A., Christ, F., Schwab, M.E., 2000. Nogo-A is a myelinassociated neurite outgrowth inhibitor and an antigen for monoclonal antibody IN-1. Nature 403, 434-439.

Crutcher, K.A., 1989. Tissue sections from the mature rat brain and spinal cord as substrates for neurite outgrowth in vitro: extensive growth on gray matter but little growth on white matter. Exp. Neurol. 104, 39-54.

David, S., Aguayo, A.J., 1981. Axonal elongation into peripheral nervous system bridges after central nervous system injury in adult rats. Science 214, 931-933.

DeBellard, M.E., Tang, S., Mukhopadhyay, S., Shen, Y., Filbin, M.T., 1996. Myelin-associated glycoprotein inhibits axonal regeneration from a variety of neurons via interaction with a sialoglycoprotein. Mol. Cell. Neurosci. 7, 89-101.

Dong, J.M., Leung, T., Manser, E., Lim, L., 1998. cAMP induced morphological changes are counteracted by the activated RhoA small GTPase and the Rho kinase ROKalpha. J. Biol. Chem. 273, 22554-22562.

Fournier, A.E., GrandPré, T., Strittmatter, S.M., 2001. Identification of a receptor mediating Nogo-66 inhibition of axonal regeneration. Nature 409, 341-346.

GrandPré, T., Nakamura, F., Vartanian, T., Strittmatter, S.M., 2000. Identification of the Nogo inhibitor of axon regeneration as a Reticulon protein. Nature 403, 439-444.

Hasan, S.J., Nelson, B.H., Valenzuela, J.I., Keirstead, H.S., Shull, S.E., Ethell, D.W., Steeves, J.D., 1991. Functional repair of transected spinal cord in embryonic chick. Rest. Neurol. Neurosci. 2, 137-154.

Hasan, S.J., Keirstead, H.S., Muir, G.D., Steeves, J.D., 1993. Axonal regeneration contributes to repair of injured brainstem-spinal neurons in embryonic chick. J. Neurosci. 13, 492-507.

Hatten, M.E., 1985. Neuronal regulation of astroglial morphology and proliferation in vitro. J. Cell. Biol. 100, 384-396.

Hirose, M., Ishizaki, T., Watanabe, N., Uehata, M., Kranenburg, O., Moolenaar, W.H., Matsumura, F., Maekawa, M., Bito, H., Narumiya, S., 1998. Molecular dissection of the Rho-associated protein kinase (p160ROCK)-regulated neurite remodeling in neuroblastoma N1E-115 cells. J. Cell. Biol. 141, 1625-1636.

Huang, D.W., McKerracher, L., Braun, P.E., David, S., 1999. A therapeutic vaccine approach to stimulate axon regeneration in the adult mammalian spinal cord. Neuron 24, 639-647.

Huber, A.B., Weinmann, O., Brosamle, C., Oertle, T., Schwab, M.E., 2002. Patterns of Nogo mRNA and protein expression in the developing and adult rat andafter CNS lesions. J. Neurosci. 22, 3553-3567.

Ishizaki, T., Uehata, M., Tamechika, I., Keel, J., Nonomura, K., Maekawa, M., Narumiya, S., 2000. Pharmacological properties of Y-27632, a specific inhibitor of rho-associated kinases. Mol. Pharmacol. 57, 976-983.

Johnson, P.W., Abramow-Newerly, W., Seilheimer, B., Sadoul, R., Tropak, M.B., Arquint, M., Dunn, R.J., Schachner, M., Roder, J.C., 1989.
Recombinant myelin-associated glycoprotein confers neural adhesion and neurite outgrowth function. Neuron 3, 377-385.

Kalil, K., Reh, T., 1982. A light and electron microscopic study of regrowing pyramidal tract fibres. J. Comp. Neurol. 211, 265-275.

Kapfhammer, J.P., Schwab, M.E., 1994a. Increased expression of the growth-associated protein GAP-43 in the myelinfree rat spinal cord. Eur. J. Neurosci. 6, 403-411.

Kapfhammer, J.P., Schwab, M.E., 1994b. Inverse patterns of myelination and GAP-43 expression in the adult CNS: neurite growth inhibitors as regulators of neuronal plasticity? J. Comp. Neurol. 340, 194-206.

Keirstead, H.S., Hasan, S.J., Muir, G.D., Steeves, J.D., 1992. Suppression of the onset of myelination extends the permissive period for the functional repair of embryonic spinal cord. Proc. Natl Acad. Sci. 89, $11664-11668$.

Keirstead, H.S., Dyer, J.K., Sholomenko, G.N., McGraw, J., Delaney, K.R., Steeves, J.D., 1995. Axonal regeneration and physiological activity following transection and immunological disruption of myelin within the hatchling chick spinal cord. J. Neurosci. 15, 6963-6974.

Lang, P., Gesbert, F., Delespine-Carmagnat, M., Stancou, R., Pouchelet, M., Bertoglio, J., 1996. Protein kinase A phosphorylation of RhoA mediates the morphological and functional effects of cyclic AMP in cytotoxic lymphocytes. EMBO J. 15, 510-519.

Laudanna, C., Campbell, J.J., Butcher, E.C., 1997. Elevation of intracellular cAMP inhibits RhoA activation and integrin-dependent leukocyte adhesion induced by chemoattractants. J. Biol. Chem. 272, 24141-24144.

Li, Y., Raisman, G., 1993. Long axon growth from embryonic neurons transplanted into myelinated tracts of the adult rat spinal cord. Brain Res. 629, 115-127.

McKerracher, L., David, S., Jackson, D.L., Kottis, V., Dunn, R.J., Braun, P.E., 1994. Identification of myelin-associated glycoprotein as a major myelin-derived inhibitor of neurite growth. Neuron 4, 805-811.

Mukhopadhyay, G., Doherty, P., Walsh, F.S., Crocker, P.R., Filbin, M.T., 1994. A novel role for myelin-associated glycoprotein as an inhibitor of axonal regeneration. Neuron 13, 757-767.

Niederöst, B.P., Zimmermann, D.R., Schwab, M.E., Bandtlow, C.E., 1999. Bovine CNS myelin contains neurite growthinhibitory activity associated with chondroitin sulphate proteoglycans. J. Neurosci. 19, 8979-8989.

Niederöst, B., Oertle, T., Fritsche, J., McKinney, R.A., Bandtlow, C.E., 2002. Nogo-A and MAG mediate neurite growth inhibition by antagonistic regulation of RhoA and Rac1. J. Neurosci. in press.

Oertle, T., Gillieron, O., Bandtlow, C.E., Schwab, M.E., 2001. Molecular and genomic characterization of the Nogo/reticulon family of proteins. Neurosci. Abstr. 258.9.

Oertle, T., van der Haar, M.E., Bandtlow, C.E., Huber, A.B., Simonen, M., Schnell, L., Brösamle, C., Schwab, M.E. Nogo-A: a molecule with three active sites and two membrane topologies, submitted for publication.

Prinjha, R., Moore, S.E., Vinson, M., Blake, S., Morrow, R., Christie, G., Michalovich, D., Simmons, D.L., Walsh, F.S., 2000. Inhibitor of neurite outgrowth in humans. Nature 403, 383-384.

Richardson, P.M., McGuinness, U.M., Aguayo, A.J., 1980. Axons from CNS neurons regenerate into PNS grafts. Nature 284, 264-265.

Ren, X.D., Kiosses, W.B., Schwartz, M.A., 1999. Regulation of the small GTP-binding protein Rho by cell adhesion and the cytoskeleton. EMBO J. $18,578-585$.

Saunders, N.R., Kitchener, P., Knott, G.W., Nicholls, J.G., Potter, A., Smith, T.J., 1998. Development of walking, swimming and neuronal connections after complete spinal cord transection in the neonatal opossum, Monodelphis domestica. J. Neurosci. 18, 339-355.

Savio, T., Schwab, M.E., 1990. Lesioned corticospinal tract axons regenerate in myelin-free rat spinal cord. Proc. Natl Acad. Sci. USA 87, 4130-4133.

Schnell, L., Schwab, M.E., 1990. Axonal regeneration in the rat spinal cord produced by an antibody against myelin-associated neurite growth inhibitors. Nature 343, 269-272. 
Schwab, M.E., Bartholdi, D., 1996. Degeneration and regeneration of axons in the lesioned spinal cord. Physiol. Rev. 76, 319-370.

Shewan, D., Berry, M., Cohen, J., 1995. Extensive regeneration in vitro by early embryonic neurons on immature and adult CNS tissue. J. Neurosci. $15,2057-2062$.

Song, H., Ming, G., He, Z., Lehmann, M., McKerracher, L., TessierLavigne, M., Poo, M., 1998. Conversion of neuronal growth cone responses from repulsion to attraction by cyclic nucleotides. Science $281,1515-1518$.

Thallmair, M., Metz, G.A.S., Z' Graggen, W.J., Raineteau, O., Kartje, G.L., Schwab, M.E., 1998. Neurite growth inhibitors restrict structural plasticity and functional recovery following corticospinal tract lesions. Nature Neurosci. 1, 124-131.

Tolbert, D.L., Der, T., 1987. Redirected growth of pyramidal tract axons following neonatal pyramidotomy in cats. J. Comp. Neurol. 260, 299-311.
Treherne, J.M., Woodward, S.K., Varga, Z.M., Ritchie, J.M., Nicholls, J.G., 1992. Restoration of conduction and growth of axons through injured spinal cord of neonatal opossum in culture. Proc. Natl Acad. Sci. USA $89,431-434$.

Turnley, A.M., Bartlett, P.F., 1998. MAG and MOG enhance neurite outgrowth of embryonic mouse spinal cord neurons. NeuroReport 9, 1987-1990.

Zagrebelsky, M., Buffo, A., Skerra, A., Schwab, M.E., Strata, P., Rossi, F., 1998. Retrograde regulation of growth-associated gene expression in adult rat Purkinje cells by myelinassociated neurite growth inhibitory proteins. J. Neurosci. 18, 7912-7929.

Z'Graggen, W.J., Metz, G.A.S., Kartje, G.L., Thallmair, M., Schwab, M.E., 1998. Functional recovery and enhanced corticofugal plasticity after unilateral pyramidal tract lesion and blockade of myelinassociated neurite growth inhibitors in the adult rat. J. Neurosci. 18, $4744-4745$. 